\title{
Desafios docentes para a atuação no Atendimento Educacional Especializado
}

\author{
Teaching challenges in Special Education Service \\ Desafíos docentes para la actuación en la Atención Educacional \\ Especializada
}

\author{
Joce Daiane Borilli Possa \\ Mestre pela Universidade Comunitária da Região de Chapecó, Chapecó, Santa Catarina, Brasil. \\ joce.possa@unochapeco.edu.br \\ ORCID - http://orcid.org/0000-0002-3526-7448

\section{Tania Mara Zancanaro Pieczkowski} \\ Professora doutora na Universidade Comunitária da Região de Chapecó, Chapecó, Santa Catarina, Brasil. \\ taniazp@unochapeco.edu.br \\ ORCID - http://orcid.org/0000-0002-5257-7747
}

Recebido em 29 de dezembro 2019

Aprovado em 3 de agosto de 2020

Publicado em 30 de setembro de 2020

\section{RESUMO}

A proposta brasileira de Educação Inclusiva resultou no crescente acesso de estudantes com deficiência às escolas regulares. Decorrente disso, o sistema educacional brasileiro mudou significativamente quanto ao atendimento a esses educandos. O Atendimento Educacional Especializado (AEE) caracteriza-se como uma das estratégias de inclusão previstas pela Política Nacional de Educação Especial na Perspectiva da Educação Inclusiva. Este artigo evidencia uma pesquisa que objetivou compreender os desafios profissionais e os efeitos de subjetivação produzidos pelas políticas de Educação Especial no que diz respeito ao AEE. O problema de pesquisa que direcionou o estudo assim constituiu-se: Como os docentes são desafiados para operacionalizar a Política Nacional de Educação Especial no que diz respeito ao Atendimento Educacional Especializado (AEE)? Para este estudo, foram entrevistadas professoras atuantes no AEE em escolas e centros de educação infantil no oeste de Santa Catarina. O material empírico gerado por meio de entrevistas narrativas foi examinado pela perspectiva da análise do discurso, amparada em referenciais foucaultianos. $O$ estudo evidenciou como os discursos legais têm operado na subjetivação e governamento dos docentes atuantes no AEE. Os discursos inclusivos presentes nas instituições escolares e nas políticas públicas de inclusão surgem como uma forma de governamento das populações, buscam o controle e o gerenciamento do risco, além da subjetivação dos indivíduos. Contudo, os avanços no campo da educação inclusiva são evidentes e reconhecidos, e, mesmo que haja a necessidade de tensionar seus paradoxos, é essencial intensificar o processo de inclusão.

Palavras-chave: Políticas de Educação Especial; desafios docentes; Atendimento Educacional Especializado. 
http://dx.doi.org/10.5902/1984686X36231

\section{ABSTRACT}

The Brazilian proposal for Inclusive Education has resulted in the growing access of students with disabilities to regular schools. As a result, the Brazilian educational system has changed significantly in terms of attending to these students. The Special Education Service (SES) is characterized as one of the inclusion strategies foreseen by the National Policy of Special Education in the Perspective of Inclusive Education. This article shows a research that aimed to understand the professional challenges and the effects of subjectivation produced by the Special Education policies with regard to SES. The research problem that led to the study is: How are teachers challenged to operationalize the National Policy on Special Education regarding to Special Education Service (SES)? For this study, teachers working in SES were interviewed in schools and early childhood centers in western of Santa Catarina state. The empirical material generated through narrative interviews was examined by the perspective of discourse analysis, supported by Foucaultian references. The study showed how legal discourses have operated on the subjectivation and governance of teachers working in SES. Inclusive discourses present in school institutions and public inclusion policies appear as a way of governing populations, seeking the control and management of risk, as well as the subjectification of individuals. However, advances in the field of inclusive education are recognized, and, even if there is a need to stress their paradoxes, it is essential to intensify the inclusion process.

Keywords: Special Education Policies; teaching challenges; Specialized Educational Assistance.

\section{RESUMEN}

La propuesta brasileña de Educación Inclusiva resultó en el creciente acceso de los estudiantes con discapacidades a las escuelas regulares. Debido a eso, el sistema educacional brasileño cambió significativamente en cuanto al atendimiento de esos educandos. El Servicio Educativo Especializado (AEE) se caracteriza como una de las estrategias de inclusión previstas por la Política Nacional de Educación Especial en la Perspectiva de la Educación Inclusiva. Este artículo demuestra la investigación que objetivó comprender los desafíos profesionales y los efectos de la subjetivación producidos por las políticas de Educación Especial referente al Atendimiento Educacional Especializado (AEE). El problema de investigación que orientó el estudio así se constituye: ¿cómo se desafía a los docentes a operacionalizar la Política Nacional de Educación Especial en lo que se refiere al Servicio de Educación Especializada (AEE)? Para este estudio fueron entrevistadas profesoras actuantes en el AEE en escuelas y centros de educación infantil en el oeste de Santa Catarina. El material empírico generado por medio de entrevistas narrativas fue examinado por la perspectiva del análisis del discurso, amparado en referenciales foucaultianos. El estudio ha demostrado como los discursos legales han operado en la subjetivación y administración de los docentes operantes en el AEE. Los discursos inclusivos presentes en las instituciones escolares y en las políticas públicas de inclusión surgen como una forma de gestión de las poblaciones, y buscan el control y la gestión del riesgo, además de la normalización, a través de la subjetivación de los individuos. Sin embargo, los avances en el campo de la educación inclusiva son evidentes y reconocidos, y aunque hay necesidad de tensar sus paradojas, es esencial intensificar el proceso de inclusión.

Palabras clave: Políticas de Educación Especial; desafíos docentes; Atendimiento Educacional Especializado. 
http://dx.doi.org/10.5902/1984686X36231

\section{Introdução}

A análise das políticas brasileiras de educação especial possibilitou perceber as intensas movimentações nesse cenário nas últimas décadas. A educação especial, na perspectiva da educação inclusiva, proposta assumida pelo país, além de determinar a presença de todas as crianças nas escolas regulares, constitui-se e por meio do Atendimento Educacional Especializado (AEE) como uma estratégia de inclusão. A multiplicidade de normativas no campo da educação especial e as ações delas derivadas instigam a olhar para esse contexto com maior destaque.

Ao longo da história, as pessoas com deficiência foram excluídas, abandonadas e tiveram seus direitos básicos negados, incluindo o direito à vida. Apesar dos avanços, 0 processo de exclusão ainda manifesta-se quando a sociedade percebe tais pessoas como doentes ou incapazes, ou quando parte de concepções de normalidade e normatividade.

De acordo com Veiga-Neto e Lopes (2007, p. 949), as atuais políticas de inclusão vêm gerando conceitos de normalidade e anormalidade, quando tratam a diferença como diversidade. Tais políticas inclusivas têm reverberado em um processo chamado de inclusão excludente. Segundo Skliar (1999), esse processo - inclusão/excludente -, ao invés de trabalhar no sentido de que a escola possa adaptar-se aos estudantes com deficiência, acaba por reforçar os mecanismos sociais que preconizam a padronização dos indivíduos, ou ainda reforça a ideia de que estes devem adequar-se a elas - à escola e à sociedade.

Este artigo propõe-se a evidenciar as práticas de profissionais atuantes no AEE e ainda os efeitos de subjetivação produzidos pelas políticas de Educação Especial. Resulta da dissertação de mestrado em Educação da primeira autora, sob orientação da segunda autora. O estudo procurou responder como os docentes são desafiados para operacionalizar a Política Nacional de Educação Especial no que diz respeito ao Atendimento Educacional Especializado (AEE). Do problema de pesquisa derivaram as seguintes perguntas de estudo: Como o Atendimento Educacional Especializado (AEE) está previsto na Política Nacional de Educação Especial? Quais as atribuições dos professores do AEE? Como acontece o processo de formação inicial e continuada do professor do AEE? Quais os desafios narrados pelos professores atuantes no AEE no contexto escolar, na relação com as famílias, no domínio de tecnologias assistivas? As condições de trabalho/estruturais possibilitam ao professor do AEE a exequibilidade da proposta como está definida nas normativas legais? 
http://dx.doi.org/10.5902/1984686X36231

Este texto, excerto do trabalho mais amplo, detém-se, dentre as perguntas de estudo, a aspectos que tratam da formação docente e das condições de trabalho, problematizando as limitações no êxito da proposta. A abordagem acontece na interface entre o que a Política de AEE define e as narrativas docentes relativas aos desafios das atribuições profissionais.

\section{Metodologia}

A pesquisa foi realizada na Rede Municipal de Ensino de Chapecó, no oeste de Santa Catarina. Após contato inicial com a Secretaria Municipal de Educação, através do setor de Educação Especial, houve a delimitação das escolas e centros de Educação Infantil que constituíram o locus da investigação.

Como sujeitos da pesquisa, foram definidas cinco professoras atuantes no AEE em Escolas Básicas Municipais (EBM) e Centros de Educação Infantil Municipal (CEIM), localizados no município investigado, no ano de 2017. Para contemplar o número de cinco professoras (considerado adequado para o estudo proposto) a investigação contemplou o universo de 16 instituições de ensino, incluindo EBMs e CEIMs. Salientamos que o número de instituições de ensino é maior do que o número de professoras pesquisadas porque a carga horária docente em cada unidade escolar é parcial e o mesmo profissional, para complementar a carga horária, atua em mais de uma instituição e Sala de Recursos Multifuncionais (SRMF) /AEE. As escolas/CEIMs selecionados para o estudo foram elencadas a partir do levantamento da região com maior número de unidades escolares com atendimento em AEE. Em cada instituição, foi entrevistada a totalidade dos professores atuantes no AEE, garantindo o número referido de entrevistados.

Como estratégia para coleta de materialidades empíricas, optamos por entrevistas narrativas. A entrevista narrativa, para Andrade (2012, p. 173), "é uma possibilidade de pesquisa ressignificada no campo de pesquisa pós-estruturalista em uma perspectiva etnográfica". A autora afirma, ainda, que "as narrativas são constituídas a partir da conexão entre discursos que se articulam, que se sobrepõem, que se somam ou, ainda, que diferem ou contemporizam" (ANDRADE, 2012, p. 179).

Foi adotado um roteiro para conduzir as entrevistas narrativas. As materialidades empíricas (narrativas das entrevistadas) foram organizadas em agrupamentos temáticos, considerando os aspectos mais relevantes e recorrentes, e analisadas pela perspectiva da análise do discurso, amparada em referenciais foucaultianos. 
Fischer (2001) salienta, que, para Foucault, ao analisar os discursos, precisamos recusar as fáceis interpretações, a busca insistente do sentido último ou do sentido oculto das coisas. É preciso, segundo o autor,

\begin{abstract}
Desprender-se de um longo e eficaz aprendizado que ainda nos faz olhar os discursos apenas como um conjunto de signos, como significantes que se referem a determinados conteúdos, carregando tal ou qual significado, quase sempre oculto, dissimulado, distorcido, intencionalmente deturpado, cheio de 'reais' intenções, conteúdos e representações, escondidos nos e pelos textos, não imediatamente visíveis. É como se no interior de cada discurso, ou num tempo anterior a ele, se pudesse encontrar, intocada, a verdade, desperta então pelo estudioso. Para Foucault, nada há por trás das cortinas, nem sob o chão que pisamos. Há enunciados e relações, que o próprio discurso põe em funcionamento. Analisar o discurso seria dar conta exatamente disso: de relações históricas, de práticas muito concretas, que estão 'vivas' nos discursos. (FISCHER, 2001, p. 198-199).
\end{abstract}

Assim, tomamos o discurso como um "conjunto de enunciados (o que pode ser enunciável) que se apoiem na mesma formação discursiva" (FOUCAULT, 2013, p. 131). O enunciado é "uma função que cruza um domínio de estruturas e de unidades possíveis e que faz com que [estas] apareçam, com conteúdos concretos, no tempo e no espaço" (FOUCAULT, 2013, p. 143).

Foram analisadas também a Política Municipal de Educação Especial e outras normativas legais, na busca de compreender o que preveem para o Atendimento Educacional Especializado e as atribuições do professor para atuação nesses espaços.

Com relação aos cuidados éticos, o projeto foi aprovado no Comitê de Ética em Pesquisa envolvendo seres humano, na Universidade Comunitária da Região de Chapecó - UNOCHAPECÓ, sob o CAAE 69152617.0.0000.0116.

Também foram adotados os Termos de Consentimento das Instituições envolvidas, o Termo de Consentimento para uso de voz e o Termo de Consentimento Livre e Esclarecido das participantes das entrevistas.

As docentes entrevistadas foram contatadas pessoalmente em uma das unidades escolares onde atuam. Posteriormente, foram agendados horários favoráveis às professoras e realizadas as entrevistas nas instituições sugeridas por elas.

As informações que seguem visam a situar o leitor acerca do contexto das materialidades empíricas geradas. Tratam-se de professoras com tempo de atuação no AEE entre 07 meses a 10 anos, considerando a data da entrevista. 
http://dx.doi.org/10.5902/1984686X36231

Quadro 1 - Relação e caracterização dos docentes participantes das entrevistas narrativas

\begin{tabular}{|c|c|c|c|c|c|c|c|}
\hline Docente & $\begin{array}{c}\mathrm{N}^{\circ} \text { de } \\
\text { EBM/CEIM } \\
\text { onde atua } \\
\text { no AEE }\end{array}$ & $\begin{array}{c}\text { Carga } \\
\text { horária }\end{array}$ & $\begin{array}{l}\text { Regime } \\
\text { de } \\
\text { contrato }\end{array}$ & $\begin{array}{r}\text { Quantidade } \\
\text { de alunos } \\
\text { atendidos }\end{array}$ & $\begin{array}{l}\text { Tempo de } \\
\text { docência }\end{array}$ & \begin{tabular}{|c|} 
Tempo de \\
docência \\
no AEE
\end{tabular} & $\begin{array}{c}\text { Caracterização dos estudantes } \\
\text { atendidos na Sala de Recursos } \\
\text { Multifuncionais - AEE }\end{array}$ \\
\hline$A$ & 03 & $40 \mathrm{~h}$ & ACT & 21 & 08 anos & $\begin{array}{c}0 \text { a } 02 \\
\text { anos }\end{array}$ & $\begin{array}{l}\text { Autismo, síndrome de cri du chate } \\
\text { deficiência auditiva, epilepsia e } \\
\text { síndrome de Johnson; paralisia } \\
\text { cerebral, deficiência intelectual } \\
\text { leve, atraso no desenvolvimento } \\
\text { neuropsicomotor e defasagem na } \\
\text { aprendizagem, } \\
\text { síndrome de Down e deficiência, } \\
\text { intelectual; déficit de atenção com } \\
\text { hiperatividade e dislexia } \\
\text { associados. }\end{array}$ \\
\hline B & 03 & $40 \mathrm{~h}$ & ACT & 13 & 10 anos & $\begin{array}{c}04 \text { a } 06 \\
\text { anos }\end{array}$ & $\begin{array}{l}\text { Deficiência intelectual, surdez, } \\
\text { autismo, paralisia cerebral, } \\
\text { Transtorno do Déficit de Atenção } \\
\text { com Hiperatividade (TDAH) com } \\
\text { sintomatologia } \\
\text { síndrome de Down. }\end{array}$ \\
\hline $\mathrm{C}$ & 02 & $40 \mathrm{~h}$ & ACT & 22 & 02 anos & $\begin{array}{c}\text { Menos de } \\
01 \text { ano }\end{array}$ & $\begin{array}{l}\text { Baixa visão, deficiência intelectual } \\
\text { leve, moderada e severa, } \\
\text { deficiência intelectual e epilepsia } \\
\text { associados, deficiência intelectual } \\
\text { e Transtorno do Déficit de Atenção } \\
\text { com Hiperatividade (TDAH), } \\
\text { autismo, perda auditiva, perda } \\
\text { auditiva e atraso cognitivo, surdo } \\
\text { bilateral e autismo. }\end{array}$ \\
\hline $\mathrm{D}$ & 04 & $40 h$ & ACT & 14 & 10 anos & $\begin{array}{c}\text { Menos de } \\
01 \text { ano }\end{array}$ & $\begin{array}{l}\text { Síndrome de Goldenhar, } \\
\text { Síndrome de Down, autismo, } \\
\text { deficiência intelectual, atraso no } \\
\text { desenvolvimento } \\
\text { neuropsicomotor, hidrocefalia e } \\
\text { atraso no desenvolvimento } \\
\text { neuropsicomotor, síndrome de } \\
\text { Williams e atraso no } \\
\text { desenvolvimento } \\
\text { neuropsicomotor. Surdez. }\end{array}$ \\
\hline$E$ & 04 & $40 \mathrm{~h}$ & ACT & 14 & $\begin{array}{c}02 \text { anos e } \\
\text { meio }\end{array}$ & $\begin{array}{c}\text { Menos de } \\
01 \text { ano }\end{array}$ & $\begin{array}{l}\text { Autismo deficiência intelectual } \\
\text { grave, autismo severo, autismo } \\
\text { leve e síndrome de Down. }\end{array}$ \\
\hline \multicolumn{4}{|c|}{ Total de docentes entrevistadas: } & \multicolumn{4}{|r|}{ (2) - } \\
\hline \multicolumn{4}{|c|}{ Total De escolas atendidas: } & \multicolumn{4}{|l|}{16} \\
\hline \multicolumn{4}{|c|}{ Total de alunos } & \multicolumn{4}{|l|}{84} \\
\hline
\end{tabular}

Fonte: Elaborado pelas autoras (2018).

${ }^{*}$ ACT - Admitido em Caráter Temporário 
http://dx.doi.org/10.5902/1984686X36231

Quadro 2 - Relação do número de EBMS/CEIMS e quantidade de alunos atendidos pelas docentes participantes das entrevistas narrativas

\begin{tabular}{|c|c|c|}
\hline Docente & EBMs/CEIMs & Número de alunos atendidos por instituição \\
\hline \multirow[b]{3}{*}{ A } & EBM - A & 11 \\
\hline & EBM -B & 10 \\
\hline & CEIM - C & Assessoria para pais e professores \\
\hline \multirow[b]{3}{*}{ B } & EBM - D & 12 \\
\hline & CEIM - E & 01 \\
\hline & CEIM - F & 01 (afastado por atestado médico) \\
\hline \multirow[b]{2}{*}{ C } & EBM - G & 20 \\
\hline & CEIM - H & 02 \\
\hline \multirow{4}{*}{ D } & EBM - I & 14 \\
\hline & EBM - J & Sala de recursos em reforma por problemas no telhado \\
\hline & CEIM - K & Não possui sala de recursos. O atendimento é feito na EBM I \\
\hline & CEIM -L & Assessoria para professores e aluno com TDAH \\
\hline \multirow{4}{*}{$\mathrm{E}$} & EBM - M & 02 \\
\hline & EBM - N & 10 \\
\hline & EBM - O & 01 \\
\hline & CEIM - P & 01 \\
\hline
\end{tabular}

Fonte: Elaborado pelas autoras (2018).

A pesquisa contemplou entrevistas narrativas com cinco docentes, que atuam em 16 escolas e atendem 84 alunos com distintas deficiências. Além desse atendimento, as docentes prestam assessoria a outros professores, pais e alunos.

Com o quadro apresentado, visamos explicitar o contexto de atuação das professoras do AEE, o que evidencia os desafios do trabalho desenvolvido.

\section{Aspectos conceituais e normativos da Educação Especial e do Atendimento Educacional Especializado (AEE)}

O aumento de alunos com deficiência na escola regular decorre de um conjunto de marcos internacionais e nacionais que explicitam o princípio da inclusão. Dentre os marcos nacionais que buscam assegurar os direitos das pessoas com deficiência destacamos a Lei de Diretrizes e Bases da Educação Nacional de 1996 (LDB 9.394/96); a Política Nacional de Educação Especial na Perspectiva da Educação Inclusiva (BRASIL, 2008); o Decreto $\mathrm{n}^{\circ}$ 7.611 de 17 de novembro de 2011 e a Lei Brasileira de Inclusão 13.146/2015. 
http://dx.doi.org/10.5902/1984686X36231

Como uma das possíveis estratégias para a inclusão, a LDB 9.394/96 menciona o Atendimento Educacional Especializado (AEE), serviço prestado nas salas de recursos multifuncionais. O parágrafo III do artigo 4ํำ da referida legislação prevê:

III - Atendimento Educacional Especializado gratuito aos educandos com deficiência, transtornos globais do desenvolvimento e altas habilidades ou superdotação, transversal a todos os níveis, etapas e modalidades, preferencialmente na rede regular de ensino. (BRASIL, 1996)

O Capítulo V, artigo 58, inciso II da referida lei, define que o Atendimento Educacional Especializado "será feito em classes, escolas ou serviços especializados, sempre que, em função das condições específicas dos alunos, não for possível a sua integração nas classes comuns do ensino regular". (BRASIL, 1996).

Na Política Nacional de Educação Especial na Perspectiva da Educação Inclusiva, o Atendimento Educacional Especializado (AEE) é entendido como:

Um serviço da Educação Especial que [...] identifica, elabora e organiza recursos pedagógicos e de acessibilidade, que eliminem barreiras para a plena participação dos alunos, considerando suas necessidades específicas. O AEE complementa e/ou suplementa a formação do aluno, visando sua autonomia, constituindo oferta obrigatória pelos sistemas de ensino. (BRASIL, 2008).

E, ainda, sobre o atendimento Educacional Especializado, o Decreto $n^{\circ} 7.611$, de 17 de novembro de 2011, em seu artigo $2^{\circ}$ destaca que "o sistema educacional deve garantir os serviços de apoio especializado voltado a eliminar as barreiras que possam obstruir o processo de escolarização de estudantes com deficiência”. (BRASIL, 2011)

Assim, pensando a inclusão a partir das noções de governamentalidade e subjetivação, desenvolvidas por Michel Foucault (2008), podemos caracterizar o AEE como uma "forma de atribuir novos contornos à Educação Especial, o que corrobora com as formas de ser e de viver na atualidade" (FRÖHLICH, 2016, p. 2). Para Foucault (2008, p. 143), a governamentalidade pode ser descrita como:

O conjunto constituído pelas instituições, os procedimentos, análises e reflexões, os cálculos e as táticas que permite exercer esta forma bem específica, embora muito complexa, de poder que tem por alvo principal a população, por principal forma de saber a economia política e por instrumento técnico essencial os dispositivos de segurança ().

Discutir as políticas de inclusão sob a ótica da governamentalidade pressupõe problematizar questões sociais, culturais, políticas e pedagógicas que poderiam ser dadas como solucionadas. Desta forma, os sujeitos capturados pela ideia de diversidade social, precisam ser aceitos e tolerados, a fim de que possam produzir experiências de inclusão. 
http://dx.doi.org/10.5902/1984686X36231

Ao referir-se à subjetivação dos sujeitos nas políticas de inclusão, Pieczkowski (2014, p. 111) afirma que:

\begin{abstract}
O sistema de ensino, nesse contexto, funciona como um mecanismo normatizador e normalizador. Os anormais precisam ser capturados pelo Estado, para terem suas condutas reguladas, controladas e serem computados nos índices de expansão de acesso à educação. A população precisa ser governada para naturalizar a diferença e para conviver com a deficiência sem estranhamentos. A discursividade em torno das políticas de inclusão se materializa nas pedagogias que colocam em circulação determinados regimes de verdade amparados no direito à igualdade, aqui entendida como garantia de acesso e permanência para todos, ou à diferença, entendida como a singularidade nos processos de aprendizagem e temporalidades distintas.
\end{abstract}

Deste modo, e amparando-nos em Lopes (2009), podemos dizer que as práticas de inclusão e exclusão operam na sociedade utilizando ainda outros instrumentos como forma de manter, o que Veiga-Neto (2001) chama de gerenciamento de risco. Em outras palavras, uma forma de sustentar o argumento de que a inclusão e a exclusão, constituídas num sistema de Estado neoliberal, são importantes para que as "pessoas possam operar com a lógica da inclusão em todas as suas ações” (LOPES, 2009, p. 154).

Deste modo, ao retomar às normativas referentes ao AEE, salientamos o Decreto no 7.611, de 17 de novembro de 2011, que dispõe sobre o Atendimento Educacional Especializado e seu financiamento. No referido Decreto, em seu Art. 2ํㅗ $§ 1^{\circ}$, o AEE é definido como: "O conjunto de atividades, recursos de acessibilidade e pedagógicos organizados institucionalmente, prestado de forma complementar ou suplementar à formação dos alunos no ensino regular" (BRASIL, 2011). Os principais objetivos previstos neste Decreto são:

I - prover condições de acesso, participação e aprendizagem no ensino regular aos alunos referidos no art. 101;

II - garantir a transversalidade das ações da Educação Especial no ensino regular;

III - fomentar o desenvolvimento de recursos didáticos e pedagógicos que eliminem as barreiras no processo de ensino e aprendizagem; e

IV - assegurar condições para a continuidade de estudos nos demais níveis de ensino. (BRASIL, 2011)

Ao referir-se às atribuições do professor de AEE e ao processo de capacitação docente, a Resolução no 04, de 02 de outubro de 2009, que institui as Diretrizes Operacionais da Educação Especial para o Atendimento Educacional Especializado na Educação Básica, prevê que "[...] para atuação no AEE, o professor deve ter formação 
http://dx.doi.org/10.5902/1984686X36231

inicial que o habilite para o exercício da docência e formação específica na Educação Especial, inicial ou continuada" (BRASIL, 2009a, p. 04).

No que se refere às atribuições do professor para atuação no AEE, a resolução ํㅜ 4, de 2 de outubro de 2009, estabelece:

I - identificar, elaborar, produzir e organizar serviços, recursos pedagógicos, de acessibilidade e estratégias considerando as necessidades específicas dos alunos público-alvo da Educação Especial;

II - elaborar e executar plano de Atendimento Educacional Especializado, avaliando a funcionalidade e a aplicabilidade dos recursos pedagógicos e de acessibilidade;

III - organizar o tipo e o número de atendimentos aos alunos na sala de recursos multifuncionais;

IV - acompanhar a funcionalidade e a aplicabilidade dos recursos pedagógicos e de acessibilidade na sala de aula comum do ensino regular, bem como em outros ambientes da escola;

$\mathrm{V}$ - estabelecer parcerias com as áreas intersetoriais na elaboração de estratégias e na disponibilização de recursos de acessibilidade;

$\mathrm{VI}$ - orientar professores e famílias sobre os recursos pedagógicos e de acessibilidade utilizados pelo aluno;

VII - ensinar e usar a tecnologia assistiva de forma a ampliar habilidades funcionais dos alunos, promovendo autonomia e participação;

VIII - estabelecer articulação com os professores da sala de aula comum, visando à disponibilização dos serviços, dos recursos pedagógicos e de acessibilidade e das estratégias que promovem a participação dos alunos nas atividades escolares. (BRASIL, 2009a, p. 3).

Desse modo, o AEE realizado em Salas de Recursos Multifuncionais, constitui-se no suporte que vai contribuir para a permanência dos alunos da Educação Especial na escola regular, logo, é requisito o investimento na qualificação e na formação do professor atuante no AEE.

A regulamentação do AEE, na Rede Municipal de Chapecó dá-se, pelas Resoluções: COMED nº 001, de 15 de dezembro de 2011, que fixa normas para a Educação Especial do Sistema Municipal de Ensino de Chapecó; e COMED nํ002, de 15 de dezembro de 2009, que estabelece diretrizes para a avaliação do processo ensino-aprendizagem nas Instituições de Educação Básica do Sistema Municipal de Ensino.

Segundo a Resolução 001/2011, o AEE é assim mencionado:

O município, através da Secretaria de Educação, disponibilizará de forma indireta mediante os Centros de Atendimento Educacional Especializados em Educação Especial e diretamente na rede municipal de ensino, serviços de Educação Especial para apoiar, complementar ou suplementar a aprendizagem dos alunos de que trata esta Resolução. (CHAPECÓ, 2011, p. 6).

Ainda segundo a Resolução no 001, o AEE também oferece "assessoramento sistemático às instituições educativas, independente da esfera administrativa com previsão 
http://dx.doi.org/10.5902/1984686X36231

e provisão de recursos para deslocamento do profissional entre as unidades escolares" (CHAPECÓ, 2011, p. 4).

Diante do proposto, fica evidenciada a centralidade do AEE na Política Nacional de Educação Especial na Perspectiva da Educação Inclusiva e ainda a formação generalista dos docentes atuantes nas salas de recursos multifuncionais.

Cabe ressaltar que a discussão em torno da formação de professores, generalistas ou especialistas, não é recente na Educação Especial. Bueno (1999, p. 21) escreveu, há quase duas décadas, que esta discussão pode ser atribuída à "absoluta indefinição, expressa pela total ambiguidade em termos de locus de formação, expressa a falta de política clara, consistente e avançada em relação à formação dos professores" (). Segundo ele, tais discussões só poderão ser remediadas através de uma política de formação de professores que considere a "ampliação efetiva das oportunidades educacionais a toda e qualquer criança, com necessidades educativas especiais ou não” (Bueno, 1999, p. 24). Destacamos essa contribuição do autor por considerarmos que os seus apontamentos relativos à formação e à atuação profissional do professor da Educação Especial ainda são presentes.

\section{Narrativas docentes: experiências de governamentalidade e subjetivação ${ }^{2}$}

A política de Educação Especial na Perspectiva da Educação Inclusiva adotada pelo país desde 2008 operou mudanças na formação e na atuação dos professores, tanto da escola regular quanto dos professores que atuam na Educação Especial. Passou de uma atuação mais especializada, com atendimento individualizado, para uma atuação mais abrangente. Em outras palavras, tal professor passa a atuar com alunos com diferentes deficiências. "O modelo de atendimento proposto pela atual política faz do professor de Educação Especial um ser multifuncional, denominação atribuída às salas de recursos que atendem a todos os tipos de alunos da modalidade" (GARCIA, 2013, p. 115).

Diante da necessidade de dar conta da multiplicidade e abrangência de atendimentos a serem realizados, o professor da Educação Especial passa a ser, nas palavras de Michels (2011), um gestor de recursos de aprendizagem, ou seja, precisa administrar, a todo o momento, a produção de novos conhecimentos.

A formação docente parece seguir a lógica neoliberal e atender às finalidades do Estado, pois "sujeitos que regulam sua própria conduta exigem um mínimo de investimento 
http://dx.doi.org/10.5902/1984686X36231

de poder, já que cada um é pastor de si mesmo" (MACHADO, 2011, p. 67). Assim, no terreno da formação docente para inclusão, verificamos que os professores são estimulados a gestar sua própria formação.

Evidenciamos, nesse tópico, excertos de narrativas das cinco docentes entrevistadas, mais especificamente em relação à formação docente e às condições de trabalho. Os recortes foram definidos por representar recorrências, expressas com diferentes dizeres.

O relato das Docentes $A$ e $B$ evidenciam a dinâmica pela constante busca de aperfeiçoamento e inovação na prática inclusiva.

(DOCENTE A) Tenho graduação em Pedagogia, para séries iniciais e educação infantil. Antes de terminar a graduação eu já fui para a pós, fazer a pós. Daí eu fiz a pós em séries iniciais e educação infantil. Daí a gente fez esse curso a distância do AEE, pela Universidade Federal de Santa Maria. Além da especialização do AEE, eu fiz mais um curso de especialização pela Universidade Federal de Uberlândia, em língua de sinais. Eu fiz mais um de altas habilidades e superdotação pela Federal de Uberlândia de 240 horas.

(DOCENTE A) Os cursos, eles dão só aquele inicial, mas você tem que buscar, você tem que ler. Você tem que procurar.

(DOCENTE B) E atualmente eu estou fazendo uma pós em neuropsicopedadogia clínica pensando em melhorar o meu trabalho lá na sala de recursos.

Essa lógica revela que a formação do docente polivalente é uma estratégia que responsabiliza o sujeito pela própria formação eficiente, na medida em que o professor é subjetivado pelos investimentos de poder. Essa relação é entendida por Foucault (1983) como processos de subjetivação. Para ele, o sujeito não só é constituinte, ele também é constituído. Dito de outra forma, Foucault (1983) faz- nos entender que o sujeito não é o centro dos processos de produção do conhecimento. O sujeito é constituído pelos processos históricos dos quais faz parte. Assim, compreender o sujeito requer a compreensão das formas de subjetivação nas quais este sujeito foi sendo construído. Essa forma de poder investida sobre o sujeito utiliza diferentes técnicas de governamentalidade.

Em estreita relação com os processos de subjetivação, emerge, na atualidade, uma nova discursividade com excepcional poder de persuasão, deslocada do setor empresarial diretamente para o setor educacional. Segundo Costa (2009), a cultura empreendedora chega ao sistema educacional festejada pelos diferentes setores da sociedade e busca fazer dos indivíduos microempresas. "Esses são caracterizados pelos seguintes traços: são proativos, inovadores, inventivos, flexíveis, com senso de oportunidade, com notável capacidade de provocar mudanças, etc" (Costa, 2009, p. 181). 
http://dx.doi.org/10.5902/1984686X36231

A proposta de cultura empreendedora revela-se nos relatos das Docentes E, B e D.

(DOCENTE E) Então, na verdade, Libras eu sabia bastante, mas daí eu esqueci porque eu nunca tive aluno surdo. Mas ano que vem a minha principal meta é fazer o curso de Libras.

(DOCENTE B) Porque não basta eu ter uma formação de AEE. Precisa buscar mais. [...] Comentaram comigo, lá da Secretaria de Educação, que receberam professores esse ano na sala de recursos que não tinham noção do que era o plano de AEE.

(DOCENTE D) [...] a sala de recursos nas escolas é você e você. Você não tem como pedir ajuda para a coordenação, porque não é uma coisa que elas dominam. Elas não entendem, não é da área delas. Então, tu chegas à sala e se vira. O que é recorrência em relação à Educação Especial na escola, elas vêm recorrer a você. Tu também não podes não saber nada. Tu tens que saber. E tem coisas que tu tens que ir buscar.

A ideia de tornar-se um empreendedor de si, um empreendedor na escola, vem disseminando-se e sendo vista como algo bom e decisivo, não só para o sucesso individual, mas também para a efetivação das políticas inclusivas no país. Os relatos das Docentes $\mathrm{E}$, $B$ e $D$ revelam a busca pelo sucesso individual e a efetivação das políticas, a partir de um esforço próprio.

Costa (2009, p. 182) menciona que a iniciativa, a inovação e o aprender a aprender aparecem como elementos muito mais significativos do que o trabalho em equipe e 0 ensino. "A cultura do empreendedorismo funciona de modo a fragmentar os indivíduos em mônadas, cada uma ficando responsável apenas por si mesma".

Ao relatar que, após a formação inicial, "você tem que buscar, você tem que ler, você tem que procurar", a Docente A revela a faceta do empreendedorismo no meio educacional. Nesta esteira, cabe ao professor estar em constante busca por conhecimento. Ele torna-se responsável pelo seu aprendizado, liberando o Estado da função de formador e assumindo a corresponsabilidade pelo triunfo acadêmico dos educandos. Nesta busca pela formação contínua, o professor é subjetivado a assumir o compromisso com a formação, mesmo fora de sua carga horária de trabalho.

Ao perceber tal expressividade, a partir de nossas leituras e nossas práticas, observamos um grande número de desafios postos com relação à infraestrutura física e humana, mas, mais efetivamente, com relação às ações pedagógicas que dão suporte às diretrizes da atual política. Em outras palavras, percebemos os docentes como linha de frente nos processos de inclusão e imersos em atribuições e afazeres. Exemplos disso são os relatam das docentes $\mathrm{E}$ e $\mathrm{D}$ : 
http://dx.doi.org/10.5902/1984686X36231

(DOCENTE E) A gente é exigida e como eu sou nova, a gente quer fazer tudo certinho e a minha articuladora falou: Olha, tem que fazer assim, assim, assim, tem que fazer isso, isso, isso; e eu fui fazendo tudo conforme ela mandou.

(DOCENTE D) Mas quando você tem que atender em quatro escolas diferentes eu acho bem complicadinho sim, porque às vezes você não consegue nem conhecer a escola direito, o aluno direito.

As professoras entrevistadas destacam que a multiplicidade de escolas onde atuam com estudantes com distintas necessidades requer que elas conheçam e, se necessário, apliquem os conhecimentos relativos à Língua de Sinais, ao sistema Braille, ao Soroban, ao Tadoma, às estratégias para autonomia do estudante com deficiência no ambiente escolar, à orientação e mobilidade, às distintas tecnologias assistivas, aos recursos da comunicação alternativa e aumentativa - CAA, ao ensino da língua portuguesa na modalidade escrita para estudantes surdos, às estratégias para o desenvolvimento de processos cognitivos e enriquecimento curricular, dentre tantas demandas.

Acreditamos que dar conta de todas as atribuições é uma tarefa árdua, para não dizer impossível, caso seja necessário exercê-las concomitantemente. A angústia com relação à quantidade de atribuições presentes nas normativas aparece no relato da Docente $\mathrm{C}$, e revela a preocupação em atender à especificidade de cada aluno e de cada processo de ensino. $E$, ainda, de responder às demandas de fora da sala do AEE, de assessoria a professores, de planejamento e adequação curricular. Nesse sentido, destacamos as seguintes narrativas:

(DOCENTE C) Com relação às atribuições eu vejo que é bastante, ainda mais quando se tem bastante alunos. Porque como eu tenho 22 alunos eu preciso pensar um plano individual para 22 alunos, são 22 avaliações.

(DOCENTE C) Tem em torno de 12 segundas professoras para conversar, para pensar um processo de mediação juntos, é muita turma para você ir. [...] Você faz tudo o que eles pedem, mas se torna extremamente corrido, para você dar conta.

Nesta esteira, Vaz e Garcia (2016) afirmam que o professor do AEE acaba tornandose um "professor multifuncional". Em tal conceito, destacado pelas autoras, o professor do AEE aparece como um recurso da Política Nacional de Educação Especial na Perspectiva da Educação Inclusiva (PNEEPEI): "é multifuncional na atuação, a qual carrega em suas atribuições elementos de técnico dos materiais adaptados e gestor da política no interior da escola, afastando-o do ato de ensinar os conhecimentos científicos" (VAZ; GARCIA, 2016, p. 07). 
Em outras palavras, tal professor precisa atender às demandas da comunidade escolar, da PNEEPEI e, ainda, ater-se ao planejamento pedagógico e às funções burocráticas.

O aporte foucaultiano permite-nos compreender que nos tornamos o que somos por relações de saber e poder que estabelecemos com os outros e conosco mesmos. Aqui, as práticas de subjetivação e governamento voltam à cena. Elas aparecem, nas políticas inclusivas, operando na formação de indivíduos por intermédio da condução restrita das ações de cada sujeito envolvido. Em outras palavras, através de diferentes táticas e estratégias de governamento, buscam conduzir permanentemente as ações e a conduta dos sujeitos.

Nesta perspectiva, chamamos a atenção para o efeito de subjetividade $\mathrm{e}$ governamento estabelecidos no discurso da Docente $C$, ao referir-se ao tempo que dispõe para planejamento das ${ }^{3}$ atividades. A docente revela que, devido à quantidade de alunos que atende e ao fato de ter que se deslocar de uma escola para outra durante o horário de trabalho, perde o seu momento de intervalo.

(DOCENTE C) Eu não consigo fazer mais planejamentos, eu tenho segundas e quartas-feiras cheias e quinta; então segunda, quarta e quinta nem intervalo eu consigo fazer. Porque não dá tempo, até porque como eu tenho aluno lá na educação infantil e eu tenho aluno aqui e são só dez minutos de intervalo; até organizar a sala, fechar e subir e organizar aqui, não tem como fazer intervalo.

Esses relatos fornecem elementos para tensionar a materialidade dos discursos legais, ou seja, como estes constituem e estruturam as relações estabelecidas na escola pelas normativas. "Além de referir-se àquilo que é dito, a materialidade do discurso referese àquilo que não é dito e que concerne a gestos, atitudes, comportamentos e organização do espaço" (TEDESCHI; PAVAN, 2017, p. 778). Em outras palavras, as narrativas refletem as relações de poder-saber colocadas em ação e produtoras de significados, de práticas, de sujeitos etc., pelas políticas de inclusão. Revelam, também, a responsabilização docente para o êxito da política de AEE no contexto no qual a pesquisa foi desenvolvida.

\section{Atendimento Educacional Especializado - AEE: da obrigatoriedade à exequibilidade da proposta}


http://dx.doi.org/10.5902/1984686X36231

A formação continuada de professores tem sido alvo de muitos programas e políticas nacionais reforçados pelos movimentos e acordos internacionais. Estes movimentos vêm sendo sentidos com maior força desde 2003, quando houve a implantação do Programa Educação Inclusiva: direito à diversidade. Esse foi um momento em que as políticas de inclusão passaram a ser adotadas pelos municípios, havendo, a partir disso, a disseminação das Salas de Recursos Multifuncionais, nas quais acontece o Atendimento Educacional Especializado.

O Programa Educação Inclusiva: direito à diversidade apoia os sistemas de ensino na implantação de Salas de Recursos Multifuncionais, com materiais pedagógicos e de acessibilidade para a realização do Atendimento Educacional Especializado complementar ou suplementar à escolarização. A proposta é atender alunos matriculados nas classes comuns do ensino regular, nas quais os alunos com deficiência, altas habilidades e transtornos globais do desenvolvimento estejam matriculados.

Em paralelo à implantação das salas de recursos acontece, desde 2007, um Curso de Aperfeiçoamento de Professores do Atendimento Educacional Especializado, totalizando 40 horas anuais, ofertado pelas Redes Municipais de Ensino. Essa formação tem como objetivo disseminar as políticas inclusivas nos municípios do país e faz parte da intencionalidade da atual Política Nacional de Educação Especial na Perspectiva da Educação Inclusiva (BRASIL, 2008).

Tendo em vista toda essa dinamicidade na direção de uma Educação Especial inclusiva, parece fundamental pensar que alguns desses movimentos e políticas de inclusão perpetuam certos regimes de verdade. O conceito de regimes de verdade é apresentado por Foucault (2014, p. 85) como aquilo "que constrange os indivíduos a esses atos de verdade [...] que define, determina a forma desses atos e estabelece para esses atos condições de efetivação e efeitos específicos". Segundo Foucault (2014), cada sociedade possui seu regime de verdade, sua "política geral de verdade".

Portanto, pontuamos, a partir das análises realizadas e das materialidades coletadas, que as políticas para a Educação Especial vêm assumindo esse caráter geral de verdade e caracterizando-se como um imperativo ${ }^{4}$ de Estado, articuladas na formação inicial e continuada dos professores de AEE.

A inclusão é tida como imperativo de Estado, já que é disponibilizada a toda a sociedade e, desse modo, deve ser assumida por todos os sujeitos e instituições como compromisso. Seu caráter de imperativo dá-se pela sua abrangência e 
imposição/obrigatoriedade, de modo que ninguém pode deixar de cumpri-la. Segundo Lopes et al, 2010, p. 6).

$\mathrm{Na}$ Contemporaneidade, a inclusão ocupa lugar de imperativo de Estado. Imperativo porque o Estado toma a inclusão como um princípio categórico, que, por ser assumido como evidente por si mesmo, é imposto de formas diferenciadas e de acordo com hierarquias de participação, a todas as formas de vida, sem exceção.

Nesta lógica, a educação aparece como uma ferramenta que permite governar a população, a partir das políticas que normatizam e regulam as ações acerca da inclusão. $A$ respeito disso, evidenciamos o relato da Docente $\mathrm{C}$, que assume o compromisso imposto pela Resolução $n^{\circ} 4$ "I - Identificar, elaborar, produzir e organizar serviços, recursos pedagógicos, de acessibilidade e estratégias considerando as necessidades específicas dos alunos público-alvo da Educação Especial" (Art. 13):

(DOCENTE C) O tempo para planejar, eu vejo que teria que ter um pouquinho mais de tempo para pensar, mesmo individual. Tem que confeccionar muitas coisas e às vezes a gente não dá conta e tem que levar para casa. E essa coisa mais prática de jogo, se precisa fazer, geralmente eu levo para fazer em casa porque às vezes não dá tempo, confecção de livros, enfim.

Tal relato expressa que, para garantir a exequibilidade da proposta, a Docente C, assim como outras professoras entrevistadas, assume o compromisso de produzir materiais e planejar fora do horário de expediente. Já a Docente A relata a preocupação com a efetivação das atribuições e revela não conseguir colocá-las em prática como estão previstas na legislação:

(DOCENTE A) Eu acredito que muitas atribuições que tem na legislação necessitariam ser revistas, que nem tudo que a gente vê na legislação a gente consegue por em prática.

Ainda, ao referirem-se à amplitude e a complexidade das atribuições presentes nas normativas legais, as docentes entrevistadas revelam a inquietação por recair sobre elas todas as expectativas de inclusão na escola. Demonstram a preocupação de ter que dominar conhecimentos específicos acerca dos estudantes com distintas deficiências ou necessidades especiais e assessorar os diferentes públicos envolvidos nos processos inclusivos. 
http://dx.doi.org/10.5902/1984686X36231

\section{Considerações possíveis}

A pesquisa evidencia os desafios encontrados pelos docentes na atuação no Serviço de Atendimento Educacional Especializado (AEE). Salientamos que o Brasil é signatário da Convenção sobre os Direitos das Pessoas com Deficiência (ONU/2006) e, por meio do Decreto $n^{\circ}$ 6.949/2009 (BRASIL, 2009b), compromete-se a garantir o acesso das pessoas com deficiência a um sistema educacional inclusivo. Para isso, são necessárias medidas que garantam o acesso e a acessibilidade, de forma a assegurar a participação de forma equânime. Consta, no artigo 24 do referido Decreto, que os Estados Partes devem assegurar um sistema educacional inclusivo em todos os níveis, além da defesa da aprendizagem ao longo da vida, e para isso deverão garantir, entre outros aspectos, que as pessoas com deficiência recebam o necessário apoio educacional, definindo que "Medidas de apoio individualizadas e efetivas sejam adotadas em ambientes que maximizem o desenvolvimento acadêmico e social, de acordo com a meta de inclusão plena" (BRASIL, 2009b).

Entendemos que o AEE é uma das possibilidades de atingir esse objetivo. Dessa forma, evidenciar fragilidades e desafios docentes na atuação no serviço não significa posicionarmo-nos contra ou negarmos sua efetividade. Tratamos, sim, de apontar, por meio da pesquisa, aspectos silenciados, naturalizados e a complexidade inerente à Política Nacional de Educação Especial em relação à operacionalização do AEE, com a prudência necessária em tempos em que a Política Nacional de Educação Especial na Perspectiva da Educação Inclusiva (BRASIL, 2008) passa por adequações.

O estudo possibilita compreender que a inclusão está presente nos discursos oficiais como um imperativo legal. No entanto, tais discursos, na sua integralidade, parecem-nos improváveis de implementação sem que a complexidade da proposta seja evidenciada e sejam melhoradas as condições para sua consolidação. Foi, ainda, possível compreender que a Política Nacional de Educação Especial na Perspectiva da Educação Inclusiva opera no sentido de mobilizar todos e cada um na concretização de práticas inclusivas.

Amparamo-nos em Foucault (1971) para evidenciar a ideia de que os discursos legais são constituídos de práticas discursivas e não discursivas que formam dispositivos de poder-saber. Os relatos das docentes entrevistadas revelam que os processos de subjetivação e governamentalidade aparecem fortemente na forma como as docentes descrevem os desafios diários para atuação no AEE. Surgem, na forma como relatam suas 
ações, na relação com os colegas docentes e, principalmente, na forma como empenhamse na efetivação da Política Nacional de Educação Especial na Perspectiva Inclusiva.

As docentes relatam, em diferentes momentos, a autoculpabilização por não conseguirem executar, de forma efetiva, as atribuições das normativas legais para o AEE. Demonstram angústia e inquietações na tentativa de dar conta de um processo de inclusão que parece ser compromisso predominantemente das próprias docentes. Relatam, ainda, a dificuldade em atuar em diferentes escolas, tendo que se deslocar durante o turno para dar conta dos atendimentos, dificultando, assim, a execução das atividades, o estreitamento dos laços com alunos e famílias e a garantia do tempo determinado na legislação para cada atendimento.

Finalizamos esse texto com uma citação de Sílvio Gallo (2004), que nos diz que se aceitarmos o desafio de Foucault (1983), especialmente no que diz respeito à ética como uma forma de produção da vida, "uma Educação para muito além da disciplinarização e da técnica será necessária para fundar as possibilidades de tal Ética. Uma educação voltada para o cuidado de si mesmo e do outro, possibilitando novas formas de produção de si e de relações com os outros" (GALLO, 2004, p. 95). Queremos dizer que, para cuidar da singularidade dos estudantes que frequentam o Atendimento Educacional Especializado, o professor também deve ser cuidado e cuidar de si.

As reflexões realizadas acerca das narrativas docentes possibilitam entender que a atual política de Educação Especial insere-se nas armadilhas de uma perspectiva que generaliza os processos educacionais, tratando de forma superficial a formação docente $e$ atribuindo aos professores a corresponsabilidade pelo sucesso da inclusão. Porém, tensionar a atual política não significa negar os avanços no campo da educação inclusiva. Significa, sim, perceber que muitos passos foram dados e que é necessário se faz reavaliar e corrigir as lacunas, mas prosseguir investindo no processo de inclusão, compreendida a partir do movimento que defende a universalização dos direitos humanos. 
http://dx.doi.org/10.5902/1984686X36231

\section{Referências}

ANDRADE, Sandra dos Santos. A entrevista narrativa ressignificada nas pesquisas educacionais pós-estruturalistas. In: MEYER, Dagmar Estermann; PARAíSO, Marlucy Alves (Orgs.). Metodologias de pesquisas pós-críticas em educação. Belo Horizonte: Mazza, 2012. p. 173-194.

BRASIL. Lei no 9.394, de 20 de dezembro de 1996. Estabelece as Diretrizes e Bases da Educação Nacional. Diário Oficial [da] República Federativa do Brasil, Brasília, DF, № 248, 23 dez. 1996.

BRASIL. Ministério da Educação. Política Nacional de Educação Especial na Perspectiva Inclusiva. Brasília: MEC/SEESP, 2008. Disponível em: http://portal.mec.gov.br/index.php?option=com_docman\&view=download\&alias=16690politica-nacional-de-educacao-especial-na-perspectiva-da-educacao-inclusiva05122014\&Itemid=30192. Acesso em: 18 dez. 2018

BRASIL. Resolução CNE n 4, de 02 de outubro de 2009a. Institui Diretrizes Operacionais para o Atendimento Educacional Especializado na Educação Básica, modalidade Educação Especial. Disponível em:

http://portal.mec.gov.br/dmdocuments/rceb004_09.pdf. Acesso em: 18 dez. 2018

BRASIL. Decreto nำ 6.949 de 25 de agosto de 2009b. Promulga a Convenção Internacional sobre os Direitos das Pessoas com Deficiência e seu Protocolo Facultativo, assinados em Nova York, em 30 de março de 2007. Diário Oficial da União, Brasília, n. 163, ago. 2009.

BRASIL. Decreto $n^{\circ} 7.611$, de 17 de novembro de 2011. Dispõe sobre a Educação Especial, o Atendimento Educacional Especializado e dá outras providências. Diário Oficial [da] República Federativa do Brasil, Brasília, DF, 17 de nov. 2011. Disponível em: http://www.planalto.gov.br/ccivil_03/_Ato2011-2014/2011/Decreto/D7611.htm. Acesso em: 16 dez. 2018.

BRASIL. Lei no 13.146, de 6 de julho de 2015. Institui a Lei Brasileira de Inclusão da Pessoa com Deficiência (Estatuto da Pessoa com Deficiência). Disponível em: http://www.planalto.gov.br/CCIVIL_03/_Ato2015-2018/2015/Lei/L13146.htm. Acesso em: 19 dez. 2018.

BUENO, José Geraldo Silveira. Crianças com Necessidades Educativas Especiais: Política Educacional e a Formação de Professores: Generalistas ou Especialistas? Revista Brasileira de Educação Especial. 1999. ISSN 1413-6538 3 (5), 7-25 Disponível em:

http://www.abpee.net/homepageabpee04_06/artigos_em_pdf/revista5numero1pdf/r5_art0 1.pdf. Acesso em: 17 dez. 2018.

CHAPECÓ. Resolução COMED nํ 002, de 15 de dezembro de 2009. Estabelece Diretrizes para a avaliação do processo ensino-aprendizagem nas instituições de Educação Básica do Sistema Municipal de Ensino. Conselho Municipal de Educação, Chapecó, 2009. 
CHAPECÓ. Resolução COMED n 001, de 15 de dezembro de 2011. Fixa normas para a Educação Especial do Sistema Municipal de Ensino de Chapecó. Conselho Municipal de Educação, Chapecó, 2009.

COSTA, Silvio Gadelha. Governamentalidade neoliberal, teoria do Capital Humano e empreendedorismo. Educação \& Realidade. 34(2): 171-186 mai/ago 2009.

FISCHER, Rosa Maria Bueno. Foucault e a análise do discurso em educação. Cadernos de pesquisa. Porto Alegre: UFRGS, no 114, p. 197-223, nov. 2001.

FOUCAULT, Michel. Segurança, Território, População. Tradução Eduardo Brandão. São Paulo: Martins Fontes, 2008.

FOUCAULT, Michel. A arqueologia do saber. Rio de Janeiro: Forense Universitária, 2013.

FOUCAULT, Michel. Aulas sobre a vontade de saber: curso no collége de France. São Paulo: Editora WMF Martins Fontes, 2014.

FRÖHLICH, Raquel. Da educação especial para a educação inclusiva: deslocamentos nas/das políticas públicas. XI ANPED Sul. Reunião Científica Regional da ANPED:

Educação, movimentos sociais e políticas governamentais. Anais eletrônicos... Curitiba. Disponível em: fhttp://www.anpedsul2016.ufpr.br/portal/wp-

content/uploads/2015/11/eixo22_RAQUEL-FR\%C3\%96HLICH.pdf. Acesso em: 18 dez. 2018.

GALLO, S. Repensar a educação: Foucault. Educação \& Realidade, Porto Alegre: FACE/UFRGS, v. 29, n. 1, p. 79-97, jan./jun. 2004.

GARCIA, Rosalba. Política de Educação Especial na perspectiva inclusiva e a formação docente no Brasil. Revista Brasileira de Educação. v. 18 p. 101-239, n. 52 jan./mar. 2013.

LOPES, Maura Corsini. Políticas de inclusão e governamentalidade. In: Educação \& Realidade, Dossiê Governamentalidade e Educação, v. 34, n. 2, p.153-170, maio/ago. 2009, Ed. FACE/UFRGS, Porto Alegre.

LOPES, Maura Corsini et al. Inclusão e Biopolítica. Cadernos IHU Ideias, São Leopoldo, a. 8 , n. 144, 2010.

MACHADO, Fernanda de Camargo. Ser professor em tempos de diversidade: uma análise das políticas de formação docente. In: THOMA, Adriana Silva; HILLESHEIM, Betina. Políticas de Inclusão. Gerenciando riscos e governando as diferenças. EDUNISC, Santa Cruz do Sul, 2011.

MICHELS, Maria Helena. O instrumental, o gerencial e a formação à distância: estratégias para a reconversão docente na perspectiva da Educação Inclusiva. In: CAIADO, Kátia Regina Moreno; JESUS, Denise Meyrelles de; BAPTISTA, Cláudio Roberto (Orgs.). Professores e Educação Especial: formação em foco. Porto Alegre: Mediação, 2011. p. 79-90. 
http://dx.doi.org/10.5902/1984686X36231

ORGANIZAÇÃO das Nações Unidas. Convention on the Rights of Persons with Disabilities. Nova York: ONU, 2006. Disponível em:

http://www.un.org/disabilities/convention/conventionfull.shtml. Acesso em: 27 ago. 2018.

PIECZKOWSKI, Tania Mara Zancanaro. Inclusão de estudantes com deficiência na educação superior: efeitos na docência universitária. 2014. 210 f. Tese (Doutorado em Educação) Programa de Pós-Graduação em Educação. Universidade Federal de Santa Maria - UFSM, Santa Maria, 2014.

REVEL, Judht. Foucault: conceitos essenciais. Tradução de Maria do Rosário Gregolin; Nilton Milanez; Carlos Piovesani. São Carlos: Clara Luz, 2005.

SKLIAR, Carlos. A invenção e a exclusão da alteridade "deficiente" a partir dos significados da normalidade. Educação \& Realidade, Porto Alegre: FACE/UFRGS, v. 24, n. 2, p. 15-32, jul./dez. 1999.

TEDESCHI, Sirley Lizott; PAVAN, Ruth. A produção do conhecimento em educação: o pós-estruturalismo como potência epistemológica. Revista Práxis Educativa. Ponta Grossa, v. 12, n 3, p. 772 -787, set/dez. 2017.

VAZ, Kamille; GARCIA, Rosalba Maria Cardoso. Professor de Educação Especial na perspectiva da Educação Inclusiva: reflexões acerca da articulação entre o modelo de professor e o projeto de escola. XI ANPED SUL. Reunião Científica Regional da ANPED: Educação, movimentos sociais e políticas governamentais. Anais eletrônicos... Curitiba, 2016 . Disponivel em: http://www.anpedsul2016.ufpr.br/portal/wpcontent/uploads/2015/11/eixo22_KAMILLE-VAZ-ROSALBA-MARIA-CARDOSOGARCIA.pdf. Acesso em: 18 dez. 2018.

VEIGA-NETO, Alfredo. Incluir para excluir. In: LARROSA, Jorge.; SKLIAR, Carlos. (Orgs.). Habitantes de Babel: políticas e poéticas da diferença. Belo Horizonte: Autêntica, 2001. p. $105-118$.

VEIGA-NETO, Alfredo; LOPES, Maura Corsini. Inclusão e governamentalidade. Revista Educação e Sociedade, Campinas, v. 28, n. 100-Especial, p. 947-963, out. 2007. Disponível em: http://www.scielo.br/pdf/es/v28n100/a1528100.pdf. Acesso em: 20 jan. 2017.

VEIGA-NETO, Alfredo; SARAIVA, Karla. Educar como arte de governar. Currículo sem Fronteiras, v.11, n.1, p. 5-13, jan/jun 2011. Disponível em http://www.curriculosemfronteiras.org/vol11iss1articles/veiga-neto-saraiva.pdf. Acesso em: 16 dez. 2018.

WANZELER, Murilo Cunha. O cuidado de si em Michel Foucault. 2011. $127 \mathrm{f}$. (Mestrado em Educação) Programa de Pós-Graduação em Filosofia da Universidade Federal da Paraíba - UFPB, 2011. 


\section{Notas}

$1 \mathrm{O}$ Art $1^{\circ}$ refere-se ao compromisso do Estado com a educação das pessoas público-alvo da educação especial, devendo ser efetivado de acordo algumas seguintes diretrizes instituídas pelo documento.

2 Subjetivação, para Foucault (1983), designa "um processo pelo qual se obtém a constituição de um sujeito, ou, mais exatamente, de uma subjetividade" (REVEL, 2005, p. 82).

${ }^{3} \mathrm{O}$ termo governamento é indicado por diferentes autores sempre que estiver ligado à questão da ação ou do ato de governar. "[...] como o esforço de criar sujeitos governáveis através de várias técnicas desenvolvidas de controle, normalização e moldagem das condutas das pessoas". (FIMYAR, 2008, p. 4, apud VEIGA-NETO; SARAIVA, 2011, p. 8).

${ }^{4}$ Refere-se a um princípio geral e incondicional, imposto a todos, a todo o tempo, independente de status. (WANZELER, 2011, p. 43).

\section{Correspondência}

Joce Daiane Borilli Possa - Rua Pardais, número 300, Efapi, Chapecó, Santa Catarina Brasil.

CEP: $89809-570$

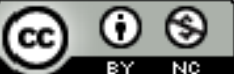

4.0 International (CC BY-NC 4.0) 